\title{
O LUGAR DO RURAL E DA RURALIDADE NA CONFERÊNCIA ESTADUAL DE ASSISTÊNCIA SOCIAL DO RN
}

\author{
RURAL AND RURALITY IN SOCIAL ASSISTANCE STATE CONFERENCE IN RN \\ EL LUGAR DEL RURAL Y DE LA RURALIDAD EN LA CONFERENCIA PROVINCIAL DE ASISTENCIA \\ SOCIAL DEL RN
}

\author{
Kamilla Sthefany Andrade de Oliveira* \\ Rafaela Palmeira Nogueira Belo** \\ Keyla Mafalda de Oliveira Amorim*** \\ Isabel Fernandes de Oliveira****
}

\begin{abstract}
RESUMO
As expressões da questão social no Rio Grande do Norte requerem ações da política de assistência social que considerem contextos rurais, cujas necessidades se particularizam. Oacesso aos serviços socioassistenciais, principalmente por quemvive em locais de difícil acesso,ainda tem sido um dos desafios dessa política universal, exigindo controle social para sua efetivação. Assim, objetivou-se analisar as demandas relativas às ruralidades para a assistência social no RN. Sistematizaram-se as teses de 161 municípios para a IX Conferência Estadual de Assistência Social (2013). Apesar de marcadamente rural,a ênfase nessa característica é recente e pouco abordada.A concentração urbana dos equipamentos socioassistenciaise as precárias condições de trabalho dos técnicosdificultama exequibilidade da política e distanciam as pessoas que vivem em contextos rurais dos direitos sociais. Instância institucionalizada de controle social, as conferências têm servido para denunciar desigualdades arraigadas àrealidade social e formas de minimizá-las, e não superá-las.
\end{abstract}

Palavras-chave: Política social. Controle social.Sistema Único de Assistência Social.

\section{ABSTRACT}

The social issues in Rio Grande do Norte require actions of social assistance policy to specific needs of rural contexts. To access at the social assistance services, especially for those who live in remote places, has still been an

\footnotetext{
* Psicóloga. Mestre em Psicologia pela Universidade Federal do Rio Grande do Norte - UFRN, Brasil. Email: millasthefany@ gmail.com

** Psicóloga. Mestre em Psicologia pela Universidade Federal do Rio Grande do Norte - UFRN, Brasil. Email: rapalmeira@gmail. com

***Psicóloga. Mestre em Psicologia pela Universidade Federal do Rio Grande do Norte - UFRN, Brasil. Email: keylamafalda@ gmail.com

****Professora Associada III do Programa de Pós-Graduação em Psicologia da UFRN, Brasil. Email: fernandes.isa@gmail.com
} 
obstacle for this social policy, requiring social control for its enforcement. This study aimed to analyze the demands on rural contexts for social assistance in the state. The proposals from 161 cities were systematized for the IX Social Assistance State Conference (2013). Although markedly rural, the emphasis on these issues is recent and little discussed. The urban concentration of social assistance equipment and precarious work conditions into social policies impede people in rural contexts to access social rights. Institutionalized instance of social control, the conferences have served to denounce inequalities rooted in social reality and ways to minimize them, not overcome them.

Keywords: Social policy. Social control. Social assistancepolicy.

\section{RESUMEN}

Las expresiones de la cuestión social en el Rio Grande do Norte requieren acciones de la política de la asistencia social que tomen en consideración los contextos rurales, cuyas necesidades se particularizan. El acceso a los servicios socio-asistenciales, principalmente por las personas que viven en localidades con difícil acceso, aún es uno de los desafíos de esta política universal, exigiendo el control social hacia su efectivización. Así, se ha objectivado analizar las demandas hacia la asistencia social en el RN que son relacionadas con las ruralidades. Se han sistematizado las tesis de los informes de 161 municipios hacia la IX Conferencia Provincial de Asistencia Social (2013). Aunque que sea marcadamente rural, la énfasis en esta característica es reciente y poco abordada. La concentración urbana de los equipamientos sociales y las condiciones precarias de trabajo en la política social oponen dificultades a la factibilidad de la política e impiden que las personas en contextos rurales puedan tener acceso a los derechos sociales. Instituciones de control social, las conferencias están a servir como espacio de denuncias de desigualdades en la realidad social y las formas de minimizarlas, sin superarlas.

Palabras Clave:Política social. Control social. Política de asistenciasocial.

\section{INTRODUÇÃO}

Em cada momento histórico,os debates sobre o meio rural apresentam diferentes perspectivas e abordagens. As próprias realidades rurais são diversas, pois, além de dependerem das transformaçóes do capitalismo mundializado, dependem também das características locais. Diante das particularidades desse fenômeno, parece mais coerente referir-se a ruralidades.

Em uma abordagem histórica mais geral, até à Revolução Industrial, o meio rural eraum espaço de importância primária para o conjunto da sociedade, 
uma vez que, se comparado ao meio urbano, tinha uma maior concentração populacional, além de ter um grande pesona economia em termos produtivos. Com o incremento da modernidade, o rural cede espaço ao urbano em nome do desenvolvimento, do progresso e da indústria (Ponte, 2004), numa relação dicotômica: rural como sinônimo de agricultura versus urbano como sinônimo de indústria, e o rural tomafeição de espaço periférico, atrasado, ultrapassado e residual(Abramovay, 2000; Pérez, 2001).

Entender o meio rural dessa maneira reforça uma concepção não apenas equivocada - quando não são poucos os exemplos de ruralidades hipermodernizadas do agronegócio -, mas que também fortalece as ideias de grandes vazios demográficos e de uma necessidade de "urbanização do campo" para "modernizá-lo", retirá-lo do "atraso". Entretanto, aplicar elementos urbanos às ruralidades não significa levá-las ao progresso; na verdade, significa adaptar as ruralidades às formas exigidas pelo capital (Abramovay, 2000; Ponte, 2004). Ou seja, o rural, o campo ou as cidades pequenassão invadidos pela lógica urbana, produzindo traços mistos derivados dessa relação (Lefebvre, 2001). Não se pretendeaqui negar as diferenças entre os dois âmbitos, mas ressaltar peculiaridades importantes para o desenvolvimento da sociedade, até mesmo as novas conjunturas que levam o meio rural a absorver aspectos urbanos, como uma estratégia de mudar seu estatuto de "carente" e recriar sua dinâmica societária, pois é inegável a diferença entre os investimentos dirigidos às cidadesquando comparados aos destinados ao meio rural.

As ciências pouco têm investido no estudo das cidades pequenas, com a justificativa de que as cidades maiores são mais complexas (Endlich, 2010). $\mathrm{Na}$ América Latina, Singer assinala que "a evolução das relações cidade-campo aparece na literatura acadêmica considerando-se principalmente as grandes concentrações urbanas travestidas de bases de conquista, de comércio ou de indústria, contrapondo-se às atividades primárias exercidas pela população rural" (Singer, como citado em Guerra, 2006, p.101). No Brasil, as definições de urbano e rural se relacionam com a história dos censos demográficos, em que "o urbano é praticamente representado pela sede municipal enquanto o rural se define pela diferença e distância do que seja o urbano" (Guerra, 2006,p.100). Apesar disso, quando as realidades das pequenas cidades são investigadas, essas sistematizações têm ganhado importância na compreensão política, econômica e social brasileira, pois privilegiam questôes pertinentes às condições de vida da população(Gonçalves, 2005; Medeiros, 2005), que podem respaldar as lutas por melhorias no acesso aos direitos sociais.

Neste estudo, entende-se o rural na unidade dialéticacidade-campo, cuja natureza se conforma a partir da histórica concentração fundiáriano Brasile da 
reestruturação produtiva que vem sendo implementada em âmbito mundial e se refletindo de forma diferenciada nos espaços regionais, seja por meio da reorganização da produção (flexibilização), das relações de trabalho (precarização do trabalho) e das lutas sociais (sindicalização dos trabalhadores, movimentos sociais, cooperativismo, etc.). Assim, a análise sobre as especificidades do âmbito rural ou das cidades pequenas compreende tanto as determinações gerais da sociedade em que estão inseridas como inclui as particularidadesdoprocesso contínuo de transformação.

A manutenção do modelo de desenvolvimento agrário desigual e excludente no Brasil radicaliza a divisão social de classes no país, com inflexão no meio rural, especialmentedo nordeste brasileiro, onde a incidência de pessoas em condição de pobreza atinge quase metade da população do campo (Nascimento, 2015; Wanderley, 2014).No RN, uma investigação que considerou as dimensões ambiental, político-institucional, econômica, espacial e social identificou que há no Estado centros urbanos isolados -Região Metropolitana de Natal, região do Seridó, Açu-Mossoró e costa salineira, e região serrana -, mas "a maior parte do Estado é composta por municípios predominantemente rurais" - região do agreste potiguar, na Chapada do Apodi, no Mato Grande e no Alto Oeste (Vale, 2011 , p. 59). A maioria dos municípios do $\mathrm{RN}(83,23 \%)$ é de pequeno porte $\mathrm{I}$, ou seja, possui população de até 20.000 habitantes (Nascimento, 2015). Nesses contextos rurais, próprios do semiárido do Nordeste brasileiro (mais de 90\% do RN está nessa condição), além da baixa renda mensal, "a distância em relação aos centros urbanos desfavorece o acesso a serviços essenciais e, nos locais de moradia, são críticas as condiçôes de saneamento, do acesso à água potável, à coleta de lixo e à eletricidade" (Wanderley, 2014, S039).

No aspecto econômico, a despeito da concentração do poder e da renda, consequência das arraigadas características coloniais no meio agrário, os pequenos agricultores familiares têm disputado e ganhado a hegemonia dos espaços rurais, principalmente em relação à produção de alimentos para população (Wanderley, 2014). As cidades pequenas seguem a tendência nacional: seu dinamismo advém da diversidade de atividades econômicas (Koga, 2004), principalmente quando há proximidade territorial aos centros urbanos (Vale, 2011), mas são os empregos públicos, as aposentadorias e os programas de transferência de rendaque têm alterado sensivelmente o mapa das desigualdades sociais,sendo o núcleo de reorientação das condiçôes de vida da população em pequenas cidades (Gonçalves, 2005; Medeiros, 2005; Wanderely, 2014).

No campo das políticas públicas, o olhar às ruralidades comparece principalmente por meio da abordagem territorial. Inicialmente,essa abordagem contemplava açôes de planejamento regional, que atendiam a diferentes projetos, 
de forma incipiente. Somente com a Constituição de 1988 o princípio da territorialidade, por meio da diretriz de descentralização, insere-se no campo das políticas públicas de forma explícita. Mais tarde, a partir do Plano Plurianual (PPA) 2004-2007 do governo federal, "surgem então vários programas governamentais sob a abordagem territorial, até mesmo com desenhos próprios para a definição de seus territórios de incidência e a criação de novas estruturas de governo para gerilos" (Silva, 2013, p. 562).Apesar dos limites do princípio de territorialização e das dificuldades para consolidá-lo, a adoção dessa perspectiva nas políticas públicas é um avanço, pois é no território que "se concretizam as manifestações da questão social e se criam os tensionamentos e as possibilidades para seu enfrentamento" (Couto, Yazbek, \&Raichelis, 2011, p. 50). Afinal, "não é demasiado insistir que as políticas é que devem responder às necessidades concretas do seu público-alvo e não o contrário" (Wanderley, 2014, p. 40).A própria existência de políticas públicas nesses espaços resultada luta e reinvindicação da classe trabalhadora que vive em contextos rurais. Nesse cenário, o incentivo à descentralização dos serviços socioassistenciais, a valorização da participação da sociedade civil, a redefinição do papel das instituições, e a importância das esferas municipais e mais precisamente das prefeituras são aspectos que ganham destaque (Shneider, 2004).

A participação da sociedade civil tem ganhado espaço institucional na gestão pública, na fiscalização, no monitoramento e no controle das ações da administração pública, aindaqueesse modelo efetivamentenãogaranta osinteresses da população (Gohn, 2004).O espaço privilegiado dessa institucionalização são as conferências particulares a cada política pública, instâncias que buscam efetivar o controle social por meio da avaliação e deliberação coletiva sobre as políticas públicas, num processo de caráter formalmente democrático e descentralizado. A relação entre o Estado, enquanto representante do povo, e a sociedade civil é mediada no espaço do controle social, no qual os conselhos são instâncias participativas que imprimem as contradições da sociedade de classes. Ou seja, o controle social é um momento de luta por hegemonia de classe no processo de gestão política, administrativo-financeira e técnico-operativa. Nessa lógica,ocontroledoEstadodeve ser exercidopelasociedade,a fim de garantir osdireitosfundamentais e os princípios democráticos (Bravo \&Correia, 2012; Correia, 2008; Silva, Medeiros, Fonseca, \&Pestano, 2008). Contudo, há limites e tensões na participação da sociedade civil nesse processo, haja vista a pressão das autoridades políticas locais na execução da política pública e a falta de autonomia da população no cotidiano dos serviços, resquícios da cultura colonial(Nascimento, 2015). 
No Sistema Único de Assistência Social (SUAS), a participação socialé institucionalizada por meio da Lei Orgânica da Assistência Social (Lei n. 8.742/1993) mas a concepção de controle social advém da Constituição Federal de 1988. Os espaços concretos para participaçãosocial sãoosconselhoseasconferências de assistência social(Brasil, 2004), que ocorrem nos três níveis da federação. No âmbito estadual, entre suas atribuições, os Conselhos Estaduais de Assistência Social, além de responsáveis pelas conferências estaduais, têm queacompanhar e controlar a execução da PolíticaEstadual de Assistência Social, regular a prestação deserviços de natureza públicae privada no campo da AssistênciaSocial, no seu âmbito, assim como assessorar os conselhos municipais. Por meio das conferências estaduais, os conselhos estaduais avaliam asituaçãodaassistênciasocial,definemdiretrizesparaesse setor dapolítica everificamosavançosocorridosnumespaçodetempodeterminado (Lei n. 8.742/1993). Apesar dos limites, as conferênciassão ferramentas importantes da sociedade civil para o planejamento, gestão e controle social das políticas de assistência social. Nesses espaços, é possível encaminhar agendas com propostas que dizem respeito às particularidades locais e regionais, assim como reivindicar ações específicas para uma população ou público-alvo.

Neste estudo, enfoca-se a IX Conferência Estadual de Assistência Socialdo Rio Grande do Norte (CEAS), que ocorreu em 2013.A etapa estadual corresponde à compilação dos relatórios da etapa municipal dos 167 municípios do RN. Oobjetivo da CEAS foi "analisar, propor e deliberar, com base na avaliação local, as diretrizes para a gestão e financiamento do Sistema Único da Assistência Social (SUAS), reconhecendo a corresponsabilidade de cada ente federado, e propor diretrizes para o aperfeiçoamento do SUAS" (Conselho Estadual de Assistência Social [CEAS], 2013).Essa Conferência teve como tema central $A$ Gestão e o Financiamento na efetivação do SUAS, cujos eixos - Cofinanciamento obrigatório da Assistência Social (eixo1); Gestão do SUAS: vigilância socioassistencial, processos de planejamento, monitoramento e avaliação (eixo 2); Gestão de Trabalho (eixo 3); Gestão dos Serviços, Programas e Projetos (eixo 4); Gestão dos Benefícios do SUAS (eixo 5); e Regionalização (eixo 6) - apresentam aspectos que tangenciam as ruralidades ou as pequenas cidades.

O objetivo deste trabalho foianalisar, no campo da assistência social, as demandas sobre ruralidade/rural/territórioapresentadas pelos municípios do RN na IX CEAS. Especificamente, buscou-se mapear e caracterizar as demandas sobre ruralidade/rural/território nas teses deliberadas e recomendadas pelos municípios do RN na IX CEAS; discutir o acesso aos equipamentos da política de assistência social pelas populações rurais;e investigar o quadro de preocupações que já foram propostas em conferências anteriores, mas permanecem como demandas do contexto rural para o controle social. 


\section{MATERIAIS E MÉTODO}

a) O plano de pesquisa seguiu os procedimentos:

b) coleta dos relatórios das Conferências Municipais de Assistência Social do $\mathrm{RN}$;

c) criação de um banco de dados para organização das teses apresentadas na etapa municipal da Conferência;

d) identificação e categorização das teses referentes às demandas rurais para a política de assistência social;

e) análise das teses sobre ruralidade e assistência social.

O Conselho Estadual de Assistência Social do RN possibilitou o acesso aos relatórios das conferências municipais. Para organização das informações, inicialmente, houve treinamento da equipe de pesquisa, a fim de sistematizar esses dados em umaplanilha eletrônica no software Excel, na qual constavam os eixos temáticos, o número de identificação dos municípios, o nome dos municípios, além das recomendações e deliberações das Conferências Municipais. Ou seja, além dos dados de identificação dos relatórios, as principais informações analisadas foram as teses (recomendações e deliberações). De acordo com o Informe n. 9/2013 do Conselho Nacional de Assistência Social (CNAS), as recomendações são deliberações anteriores cuja manutenção na agenda do SUAS foi considerada pertinente nas discussões realizadas na conferência, enfatizando-se a importância de sua implementação. Já as deliberações são propostas novas que não foram contempladas em nenhuma deliberação das conferências anteriores e que devem ser instituídas (Conselho Nacional de Assistência Social [CNAS], 2013). Essa distinção é importante por realçar a recentidade ou não da ruralidade entre as proposições da CEAS.

Após sistematizar as teses apresentadas pelos municípios do $\mathrm{RN}$ na etapa municipal, cada tese foi analisada particularmente, a fim de identificar as proposiçôesque se referiamà ruralidade e contexto rural. Para isso, empregouse numa busca no banco de dados os seguintes descritores, isolados ou em combinação: contexto rural, ruralidade, população rural, comunidades rurais, rural, itinerante, volante, busca ativa, zona rural, interiorização, interior e integralidade. Selecionadas as teses sobre ruralidades, procedeu-se à análise, com destaque para a acessibilidade das populações rurais aos serviços da assistência social, considerando a crítica marxista às políticas sociais no Estado brasileiro sob o domínio do capital. 


\section{RESULTADOS E DISCUSSÃO}

Nesses resultados, busca-se elucidar os principais dados das conferências municipais de 161 municípios do $\mathrm{RN}$, tendo em vista a não realização da etapa municipal daconferência em seis desses. Esses resultados são apresentados pelos eixos temáticos que organizaram a própria CEAS, conforme citado alhures.

O cofinanciamento obrigatório da Assistência Social,primeiro eixo, prediz a responsabilidade de cada ente federado na execução da Política Nacional de Assistência Social, levando em conta seu porte, a complexidade dos serviços prestados e as diversidades regionais. Ao analisá-lo, identificou-se que, do total das 522 teses sobre cofinanciamento, 10 referiam-se a demandas sobre ruralidade. Deliberavam sobre a busca de cofinanciamento junto ao Estado e à União para estruturação dos serviços, estrutura física adequada (incluindo transportes para prestação de serviços), formação continuada de recursos humanos com cofinanciamentocorrespondente, de forma a qualificar a oferta de serviços. Além disso, as deliberações se referiam à implantação de equipes volantes nos Centros de Referência de Assistência Social para atender as populaçôes rurais, incluindo a contratação de mais profissionais (Brasil, 2011; Nascimento, 2015).

Apesar do reconhecimento pelo Poder Executivo estadual das ações no âmbito da assistência social, como anunciado na mesa de abertura da IX CEAS, e principalmente do cofinanciamento como eixo estruturante da política, a sua execução não é garantida, sendo a função fiscalizadora do controle social essencial para o cumprimento desse objetivo.

Vale ressaltar a necessidade de se executar o cofinanciamentocontando com os três entes federados, com distribuição de recursos próprios dos fundos de assistência social por parte dos estados e dos municípios. Para tanto, algumas açóes são requeridas. Em primeiro lugar, é preciso analisar a estruturação do Fundo de Assistência Social, verificando como o Índice de Gestão Descentralizada (IGD) tem sido trabalhado, com destaque para o acompanhamento da sua execução por parte dosConselhos. É mister que o IGD priorize o aprimoramento e o fortalecimento do controle social, um de seus principais objetivos. Também é imprescindível a participação ativa dos Conselhos Municipaisde Assistência Social nos processos de elaboração, apreciação e acompanhamento da execução dos instrumentos de planejamento, ou seja, da proposta orçamentária para a área (Conselho Municipal de Assistência Social [CMAS], 2013). O não cumprimento dessas atribuiçóes pelas instâncias do controle social podem comprometer quaisquer possibilidades de financiamento de políticas estrategicamente voltadas para os contextos rurais. 
É preciso atentar para a iniquidade na distribuição dos recursos, principalmente a concentração no financiamento de serviços nas médias e grandes cidades e nas regiōes sul e sudeste do país; a excessiva segmentação do financiamento por faixa etária, ciclo de vida e vulnerabilidade específicas; a fixação de valores per capita, que destinam recursos com base no número total de atendimentos e não na conformação dos serviços às necessidades da população; os recursos financeiros "engessados" por uma série histórica de beneficiados; o burocratismo, a baixa celeridade e a descontinuidade no estabelecimento de convênios para repasse de recursos; a discrepância entre uma prestação de contas detalhada e complexa que não revela efetividade em mensurar a consecução dos objetivos financiados, entre outros aspectos. É preciso dizer que esse cenário vem se modificando, mas ainda não contempla as áreas mais distantes e de difícil acesso, em geral, áreas rurais (Brandão, 2012).

No segundoeixo, sobre Gestão do SUAS, que deve ser descentralizado e participativo, as 34 teses deliberadas sobre ruralidade na CEAS requerem ação mais ativa da Vigilância Socioassistencial. O núcleo central dessa ação em relação às ruralidades é identificar situações de risco e de vulnerabilidade social, por vezes com características particulares ou mais frequentes nesses contextos. Para concretizar a vigilância socioassistencial, é firmemente reiterada a necessidade de mais equipamentos sociais, seja os CRAS sejaequipes volantes,aliadas ao fortalecimento de busca ativa.

A Vigilância Socioassistencial trata de processos ligados diretamente à identificação de indicadores de vulnerabilidade social, de risco social e de informaçôes relevantes sobre o território (Rizzotti\&Silva, 2013). A vulnerabilidade social, uma vez que abrange aspectos individuais, sociais e programáticos, supera a noção de risco num território e envolveos valores pessoais, a prevenção, o amparo social, o acesso a informações, bem como a utilização de recursos distribuídos pelos programas da assistência social(Ayres, 2001; Saquet\& Silva, 2008). Por isso, a Vigilância Socioassistencialpode ser considerada um elemento que propicia o planejamento de ações preventivas, de aprimoramento e qualificação de várias açôes que visam a identificar e a notificar situações de vulnerabilidade social, por meio da produção de indicadores sociais a serviço das políticas públicas. No caso do contexto rural, dois aspectos que repercutem nas ações de vigilância devem ser destacados: primeiro, a centralidade da família nas formas de produção agrária, que coincide com a organização dos serviços socioassistencias ofertados no SUAS; e,segundo, a execução deprogramas focalizados para públicos em condições socioeconômicas distintas, estando em pobreza persistente parte da população rural (Wanderley, 2014). 
Quanto à Gestão do Trabalho, identificaram-se apenas cinco teses a respeito de ruralidades, dentre as 530 desse terceiro eixo da CEAS. Oponto-chave dessas deliberações refere-se à integralidade da atenção socioassistencial, além da implantação de serviços de fortalecimento de vínculos.O termo integralidadetem suas raízes já na discussão sobre os princípios e diretrizes do Sistema Único de Saúde, quando se refere à atenção integral à saúde, visando a priorizar atividades preventivas, sem prejuízo dos serviços assistenciais.

$\mathrm{O}$ atendimento integraltrata da não fragmentação da atenção e proteção dos usuários das políticas, reconhecendo a interferência dedeterminantes socioeconômicos, políticos e culturais (Pinheiro \&Matos, 2001).A construção do vínculo baseado na integralidadeimplica a responsabilização dos serviços socioassistenciaiscom o usuário, a fim degarantir o acesso universal e igualitário, em estreita relação com a defesa dos direitos sociais. A integralidade é relevante também para o grau de resolutividade e a horizontalidade da atenção, o que requer, necessariamente, a concepção de que usuários são sujeitos de direitos e, portanto, sua participação no cotidiano dos serviços socioassistenciaise nas instâncias de controle social é imprescindível (Chupel, 2005).

A relação direta com o princípio da equidade é também um aspecto relevante da integralidade. É assim que as particularidades da população rural podem ser enfocadas, a fim de garantir serviços, programas e projetos socioassistenciaisrelacionados às necessidades desse público. É bem verdade que algumas demandas tomadas de forma genérica são semelhantes a outros contextos: qualificação e geração de emprego e renda, programas e projetos para jovens e para idosos etc. Contudo, a equidade é a necessidade de se atentar para o modocomo essas iniciativas são executadas e a que demandas respondem, ou seja, como partir de determinações amplas e adequá-las segundo as características dos territórios em que sãoimplementadas. Realizar atividades com grupos geracionais em contextos urbanos e rurais, por exemplo,requer que se resgateelementos históricos, culturais, econômicos, sociais que, certamente, guardam marcas importantes ligadas a cada um desses contextos, em função de sua evolução histórica. Muito das ruralidades escapa ao urbano (e vice-versa), a exemplo das históricas lutas sociais do campesinato no país, que não têm sido pautadas nem nas políticas setorias relativas à atividade produtiva no campo, nem no SUAS. Assim, resgatar as características protetivas dos territórios urbanos e rurais e identificar as propriedades de cadaum desses certamente redundará em paisagens distintas (Wanderley, 2014). A forma genérica de qualificação profissional, por exemplo, ganha contornos particulares se considerada a sazonalidade da necessidade de força de trabalho na produção agrícola. 
O quarto eixo, Gestão dos Serviços, Programas e Projetos, composto por 530 deliberações, soma 54 teses com demandas relativas à população rural. São conteúdos dessas teses: a solicitação de programas de qualificação e geração de emprego e renda,de programas e projetos para jovens e de cursos de capacitação para a população em geral; a construção de Centros de Convivência, PróCampo, Academia da Terceira Idade; as equipes volantes dos CRAS e atividades descentralizadas também da Proteção Social Especial; a realização de palestras para a população rural. As teses desse eixo também reforçam a importância da integralidade da assistência social.

Serviços como esses estão ao alcance dos serviços da Proteção Social Básica e da Proteção Social Especial. O primeiro visa a prevenir riscos por meio do desenvolvimento de potencialidades e fortalecimento de vínculos familiares e comunitários; nesse nível, deve haver serviços, programas e projetos desenvolvidos em locais de acolhimento, convivência e socialização das famílias. O segundo nível destina-se a famílias e indivíduos em situação de risco pessoal ou social, cujos direitos foram violados ou ameaçados. O CREAS, principal equipamento desse nível de proteção, deve coordenar e fortalecer a articulação dos serviços da rede de assistência social e das demais políticas públicas (Brasil, 2009b).

Nas teses da CEAS propõem-se serviços, programas e projetos genéricos da política de assistência social, mas é importante não perder de vista as particularidades do contexto rural também nesse quesito, pois

como[os camponeses] não são considerados produtores, acena-se com a possibilidade de acesso a empregos não agrícolas, frequentemente não rurais, os quais, por sua vez, são reduzidos ou mesmo inexistentes na maioria dos pequenos municípios e raramente são objetos de políticas específicas(Wanderley, 2014, p. 41).

As 28 teses de demanda sobre o rural que compõem o eixo de Gestão dos Benefícios do SUAS(5ํ eixo) trazà tona a necessidade de efetivação da busca ativa aliadaàs equipes volantes -equipes adicionais que integramos CRAS. Essas equipes objetivam prestar serviços socioassistenciaisno seu território de abrangência, para atender às famílias que vivem em locais de difícil acesso ou estão dispersas no território:

$\mathrm{O}$ atendimento às famílias residentes em territórios de baixa densidade demográfica, com espalhamento ou dispersão populacional (áreas rurais, comunidades indígenas, quilombolas, calhas de rios, assentamentos, dentre outros), no âmbito do Serviço de Proteção e Atendimento Integral à Família, pode ser realizado por meio de equipes volantes (Brasil, 2009b, p. 6). 
A referência às ruralidades nesse eixo revela a precária gestão de benefícios, vista a dificuldade de acesso dos usuários não só aos serviços socioassistencias, mas também a um momento imediato da assistência social: o cadastramento em programas de transferência de renda. Os direitos sociais também são pouco acessíveis a esse público devido às condições objetivas de trabalho que dificultam a cobertura de todo o território pelas equipessocioassistenciais. Além disso, a gestão de benefícios relativos a outros programas, a exemplo do acesso ao crédito ou à previdência por trabalhadores rurais,é destacada nesse eixo, requerendo articulação com outros setores da política pública para efetivação dos direitos sociais.

Por fim, o último eixo da CEAS, Regionalização, contém 89 teses de demandas sobre ruralidades, das quais se destaca a necessidade de cobertura do território pelas equipes dos CRAS e dos CREAS, especialmente com a implementação de equipes adicionais para expansão dos programas e serviços socioassistenciais para zona rural e áreas de difícil acesso.

Esse eixo merece maior atenção nesta análise, não por ser mais importante que os demais, mas porque apresenta maior número, diversidade e complexidade de teses sobre ruralidade, e também porquecompila as necessidades apresentadas nos outros eixos da Conferência, como: a integralidade e, portanto, a descentralização das ações políticas, a atenção às necessidades sociais que requerem serviços regionalizados, e a consideração da diversidade regional, ou seja, das particularidades da população rural. Por princípio, esse eixo leva em consideração o contexto rural como ponto de partida das demandas dos usuários da assistência social.

Algumas recomendações desse eixomerecem destaque: "Tratamento igualitário aos cidadãos das zonas urbana e rural no acesso às políticas públicas" (CEAS, 2013), "Garantir a universalização do atendimento" (CEAS, 2013), "Efetivação pelo ente estadual dos serviços regionalizados de média e alta complexidade" (CEAS, 2013), "Definir uma política de expansão dos serviços socioassistenciaisdestinados ao atendimento da população rural" (CEAS, 2013). As razôes para esse destaque provêm da constatação de que há uma dificuldade adicional de cobertura e de acesso aos serviços socioassistenciais pela população rural. As diversas secretarias do Ministério de Desenvolvimento Agrário (MDA) têm incentivado ações de valorização humana e da política, considerando os desejos e os anseios das organizações sociais, praticando os princípios da descentralização, da democracia e da participação social. Todavia, segundo Silva (2004), o caráter de universalidade que o Estado tem buscado favorecer não pode se realizar numa sociedade capitalista, porque "há de se entender que o desenvolvimento capitalista é por si mesmo contraditório: cria e destrói; gera 
riqueza de um lado e miséria de outro" (Silva, 1998, p. 60). Sob essalógica, no limite,a melhoria das condições de vida da classe trabalhadora avança até o ponto em que esse movimento não impeça ou prejudique sobremaneira a acumulação do capital.

No que diz respeito às Recomendações (ou seja, teses apresentadas em Conferências anteriores, mas não executadas pela gestão pública), a IX CEAS contou com 969 teses, sendo que dessas apenas 27 relacionam assistência social e ruralidade, demonstrando a recentidade da ênfase nessa questão, a despeito das arraigadas características que acompanham a realidade social das populaçõos rurais. A maior parte dessas teses está concentrada nos eixos4 e 6 (Gestão dos Serviços, Programas e Projetos e Regionalização, respectivamente). Assim, referem-se à ausência de ações voltadas para a renda da população rural, à ausência da busca ativa e de equipes volantes, enfatizando a necessidade de valorização da diversidade regional. Embora a quantidade de recomendações seja pequena, essas não destoam das deliberações apresentadas na IX CEAS: ainda que a cobertura de serviços socioassistenciais tenha crescido, a implementação de equipes adicionais nos CRAS e de CREAS é mencionadacomo não existente ou como não tendo atingido a população rural,seja porque esse público está em locais de difícil acesso, seja pelas condições de trabalho dos técnicos - com destaque para a ausência de infraestrutura, especialmente veículos para cobertura de territórios extensos, e de pessoal, contando com um número insuficiente de profissionais ou com profissionais não capacitados para suprir as demandas dessa população, o que se traduz na precariedade de serviços, programas e projetos (Nascimento, 2015).

De modo geral, as teses de cada município de pequeno, médio ou grande porte não destoam. Se fosse possível resumir as preocupações com a assistência social ao público rural na IX CEAS numa só deliberação, o enunciado seria: "buscar cofinanciamento junto ao Estado e à União para estruturação dos serviços, estruturas físicas adequadas, formação continuada e transportes para prestação de serviços, e um cofinanciamento maior para os recursos humanos, que qualificar e ofertar um melhor serviço em toda área de abrangência, inclusive a zona rural' (grifo nosso).De todo modo, as demandas sobre ruralidades são mais apresentadas em municípios de pequeno e médio porte, que somam a maior parte dos municípios do Estado.

\section{CONSIDERAÇŌES FINAIS}

A IX CEAS é considerada um momento importante de debates e deliberações para a Política de Assistência Socialem âmbito estadual, uma vez que busca 
aprimorar a gestão e o financiamento do SUAS no RN para os próximos dois anos. As conferênciassão espaços de controle social, considerado o âmbito oficialde participação democrática, construído a partir de propostas coletivas. Nessa conferência, houve uma posição mais forte quanto às deliberações relativas à relação entre assistência social eruralidade, quando se identificam teses inéditas sobre o tema. Isso pode indicar avanços nas discussões sobre as deliberações e recomendações descritas para a consolidação do SUASCMAS, 2013).

Considerando o rural como uma totalidade forjada no nível macroestrutural por uma dinâmica societária que produz desigualdade social, esse mesmo rural também se produz em meio às relações sociais, que podem ser incentivadoras de diversos debates, de lutas e reinvindicaçôes. Muito embora haja dificuldades na discussão daquilo que é peculiar às populações rurais, é perceptível que estão sendo engendradas ações políticas, contraditórias ou não, de maior participação popular e de caráter democrático. Entretanto, este estudo revela que as populaçóes rurais de alguns municípios do Estado do $\mathrm{RN}$ estão com baixo acesso a serviços e programas da assistência social.

As demandas sobre ruralidades têm sido, aos poucos, postas em pauta, mas ainda não vêm sendo uma prioridade. A efetivação da política e a concretização das mudanças demandadas em relação às ruralidades envolvem uma série de desafios concretos, as peculiaridades territoriais, o difícil acesso geográfico, a precária infraestrutura e, principalmente, o próprio lugar que o social ocupa na política pública, que se funda nas marcas históricas que permeiam a assistência social, da oferta de serviços pobres para pobres, de forma burocratizada e inoperante, "percebida como benevolência paliativa, renegada como secundária e marginal ao conjunto das políticas" (Yasbek, 2006, p. 49).

Superar esse quadro não é tarefa simples, afinal, a assistência social tem o desafio "de concretizar os direitos de cidadania em um período em que a ordem capitalista vigente é contrária a esse processo" (Pereira \&Teixeira, 2013, p.10). As bases de sustentação da lógica capitalista predominam sobre as necessidades verdadeiramente humanas, de modo a fazer com que a reprodução social dos indivíduos e da totalidade social esteja a serviço da burguesia. Essa processualidade opera sob o discurso da igualdade formal, política e jurídica, retratada neste estudo pela importância da participação da sociedade civil no controle social, mas que mantém e reproduz a desigualdade social. Essa direção política pode ser observada nos próprios eixos da CEAS, que enfocam a gestão técnica da política pública, sem espaço para que emerjam tensionamentos da classe trabalhadora organizada. A ausência de teses da CEAS que recuperem as lutas do campesinato por políticas de distribuição de terras ou por políticas de recursos hídricos para uma região de seca persistente revelam quão distante essas propostas estão das 
condiçôes de vida concretas dessa realidade social. Ainda que se considere que é preciso forçar os limites da política pública em prol da classe trabalhadora, não se pode perder de vista seu caráter progressista, ou seja, que a afirmação de igualdade nesse projeto societário é o objetivo velado de se manter a dominação (Lessa \&Tonet, 2011). 


\section{REFERÊNCIAS}

Abramovay, R. (2000). Funções e medidas da ruralidade no desenvolvimento contemporâneo. Texto para discussão n. 702. Rio de Janeiro: IPEA. Recuperado a partir de http://www.ipea.gov.br/portal/images/stories/PDFs/TDs/td_0702. pdf

Ayres, J. R. C. M. (2001). Sujeito, intersubjetividade e práticas de saúde. Ciência \& Saúde Coletiva, 6(1), 63-71. Recuperado a partir de http://www.redalyc.org/ pdf/630/63060105.pdf

Brandão, F. A. (2012). Políticas Públicas: o financiamento público da assistência social. [S.l.]: Portal Social. Recuperado a partir de http://portalsocial. sedsdh.pe.gov.br/sigas/suasrh/arquivos/2013/modulo01/recife2/O\%20 FINANCIAMENTO \%20PUBLICO $\% 20$ DA $\% 20 A S S I S T E N C I A \% 20$ SOCIAL.pdf

Brasil. Ministério do Desenvolvimento Social e Combate à Fome (2004). Política Nacional de Assistência Social - PNAS/2004. Brasília: MDS.

Brasil. Ministério do Desenvolvimento Social E Combate À Fome (2009a). Orientaçôes Técnicas: Centro de Referência de Assistência Social - CRAS. Brasília:MDS.

Brasil. Ministério do Desenvolvimento Social e Combate à Fome. (2009b). Tipificação Nacional de Serviços Socioassistenciais. Brasília:MDS.

Brasil. Ministério do Desenvolvimento Social e Combate à Fome. (2011). Resumo Executivo das Orientaçôes para execução de Serviços de Proteção Social Básica e ações por Equipes Volantes. Brasília:MDS.

Bravo, M. I. S., \& Correia, M. V. C. (2012). Desafios do controle social na atualidade. Serviço Social \& Sociedade, 109, 126-150. Recuperado a partir de http://www.scielo.br/scielo.php?script=sci_ arttext\&pid=S010166282012000100008\&lng=en\&tlng=pt

Chupel, C. P. (2005). O acolhimento em saúde para os profissionais do Serviço Social: uma reflexão baseada no princípio da integralidade e sua relevância junto aos processos socioassistenciais. (Monografia de Trabalho de Conclusão de Curso). Universidade Federal de Santa Catarina, Florianópolis.

Conselho Estadual de Assistência Social(2013). Regimento Interno. InAnais, 9 Conferência Estadual de Assistência Social do Rio Grande do Norte. Natal: SETHAS. 
Conselho Municipal de Assistência Social (2013). A gestão e o financiamento na efetivação do SUAS. In Anais, 9 Conferência Municipal de Assistência Social. Natal: SEMTAS.

Conselho Nacional de Assistência Social. (2013). In Anais, 9 Conferência Nacional de Assistência Social: esclarecimentos preliminares sobre as Conferências Estaduais de Assistência Social: informe 09/2013. [S.1.]: CNAS. Recuperado a partir de http://www.mds.gov.br/cnas/conferencias-nacionais/ix-conferencianacional/informe-009-2013_final.pdf/download

Correia, M. V. C. (2008). Controle Social. In I. B. Pereira \& J. C. F. Lima (Orgs.), Dicionário da educação profissional em saúde. (2a ed.). (pp. 66-73). Rio de Janeiro: Escola Politécnica de Saúde Joaquim Venâncio; Fiocruz. Recuperado a partir de http://www.epsjv.fiocruz.br/index.php?Area=Material \&Tipo=8\&Num=43

Couto, B. R.,Yazbek, M. C., \&Raichelis, R. (2011).A política nacional de assistência social e o SUAS: apresentando e problematizando fundamentos e conceitos. In B. R. Couto, M. C. Yazbek, M. O. S. Silva,\& R. Raichelis (Orgs.), O Sistema Único da Assistência Social no Brasil: uma realidade em movimento(pp. 32-65). São Paulo: Cortez.

Endlich, A. M. (2010). Perspectivas sobre o urbano e o rural. In M. E. B. Sposito\& A. Whitacker, M. (Orgs.), Cidade e campo:relaçôes e contradiçôes entre urbano e rural (2a ed., pp. 11-32). São Paulo: Expressão Popular.

Gohn, M. G. (2004). Emponderamento e participação da comunidade em políticas sociais. Saúde e Sociedade, 13(2), 20-31. Recuperado a partir de http:// www.revistas.usp.br/sausoc/article/download/7113/8586

Gonçalves, F. E. (2005). Cidades pequenas, grandes problemas: perfil urbano do agreste potiguar (Dissertação de Mestrado). Universidade Federal do Rio Grande do Norte, Programa de Pós-Graduação em Geografia, Natal. Recuperado a partir de http://repositorio.ufrn.br:8080/jspui/handle/123456789/18894

Guerra, G. (2006). Desenvolvimento territorial na Amazônia: rural e urbano como faces da mesma moeda. In A. C. D. Cardoso (Org.), O rural e o urbano na Amazônia: olhares em perspectivas (pp. 97-110). Belém: EDUFPA.

Koga, D. (2004). O território e suas múltiplas dimensões na Política de Assistência Social. Cadernos de Estudos Desenvolvimento Social em Debate (2 - Suplemento, pp. 17-21). Brasília:MDS.

Lefebvre, H. (2001). O direito à cidade. São Paulo: Centauro. 
Lei n. 8.742, de 07 de dezembro de 1993. (1993, 07 dezembro). Dispõe sobre a organização da Assistência Social e dá outras Providências. Diário Oficial da União, Brasília. Recuperado a partir de http://www.planalto.gov.br/ccivil_03/ leis/18742.htm

Lessa, S., \& Tonet, I. (2011). A política e o Estado democrático. In S. Lessa \& I. Tonet (Orgs.), Introdução à Filosofia de Marx (pp. 81-86). São Paulo: Expressão Popular.

Medeiros, M. S. S. (2005). A produção do espaço das pequenas cidades do Seridó Potiguar (Dissertação de Mestrado). Universidade Federal do Rio Grande do Norte, Natal. Recuperado a partir de http://repositorio.ufrn.br/jspui/ bitstream/123456789/18910/1/MariaSSM.pdf

Nascimento, M. N. C. (2015). As açôes das equipes volantes dos Centros de Referência de Assistência Social no Rio Grande do Norte (Dissertação de Mestrado). Universidade Federal do Rio Grande do Norte, Natal.

Pereira, K. Y. L., \& Teixeira, S. M. (2013). Redes e intersetorialidade nas políticas sociais: reflexões sobre sua concepção na política de assistência social. Textose Contextos, (12(1), 114-127. Recuperado a partir dehttp://revistaseletronicas. pucrs.br/ojs/index.php/fass/article/view/12990/9619

Pérez, E. C. (2001). Hacia una nueva visión de lo rural. In N. Giarracca (Org.).Una nueva ruralidad en América Latina?(pp. 17-30).Buenos Aires: Asdi/Clacso. Recuperado a partir http://biblioteca.clacso.edu.ar/clacso/ gt/20100929011414/2perez.pdf

Pinheiro, R., \& Mattos, R. A. (2001). Os sentidos da integralidade na atenção e no cuidado de saúde. Rio de Janeiro: IMS- ERJ/ABRASCO.

Ponte, K. F. (2004, Janeiro, Julho). (Re)pensando o conceito do rural. Revista Nera, 7(4), 20-28. Recuperado a partir http://revista.fct.unesp.br/index.php/ nera/article/view/1477/1453

Rizzotti, M. L. A., \& Silva, T. G. M. (2013). A vigilância social na política de assistência social: uma aproximação conceitual. Serviço Social em Revista, 15(2), 130-151.

Saquet, M. A., \& Silva, S. S. (2008). Milton Santos: concepções de geografia, espaço e território. Geo UERJ, 18(2), 24-42. Recuperado a partir dehttp:// www.e-publicacoes.uerj.br/index.php/geouerj/article/viewFile/1389/1179 
Shneider, S. (2004). A abordagem territorial do desenvolvimento rural e suas articulaçōes externas. Sociologias, 11, 88-125. Recuperado a partir http://www. scielo.br/pdf/soc/n11/n11a06

Silva, C. E. M. (2004). Políticas públicas e desenvolvimento rural: em busca de novos caminhos. In U. A. Oliveira \& M. I. M. Marques (Orgs.), O campo no século XXI: território de vida, de luta e de construção da justiça social (pp. 335352). São Paulo: Paz e Terra/Casa Amarela.

Silva, J. G. (1998). A nova dinâmica da agricultura brasileira. Campinas: Unicamp.

Silva, S. P. (2013). Consideraçôes analiticas e operacionais sobre a abordagem territorial em políticas públicas. Brasília: IPEA. Recuperado a partir de http://www.ipea.gov.br/portal/index.php?option=com content $\&$ view $=$ article $\&$ id $=19835 \&$ Itemid $=9$

Silva, V. R., Medeiros, M. R. A., Fonseca, F. F., \&Pestano, C. R. (2008). Controle Social no Sistema Único de Assistência Social: propostas, concepções e desafios". Revista Textos \& Contextos, 7(2), 250-265. Recuperado a partir de http:// revistaseletronicas.pucrs.br/ojs/index.php/fass/article/viewFile/4825/3630

Vale, F. F. R. (2011). Desenvolvimento territorial no Rio Grande do Norte: uma identificação de clusters rurais (Dissertação de Mestrado). Universidade Federal do Rio Grande do Norte, Natal). Recuperado a partir de http://repositorio. ufrn.br:8080/jspui/bitstream/123456789/18306/1/FabioFRV_DISSERT.pdf

Wanderley, M. N. B.. (2014). O campesinato brasileiro: uma história de resistência. Revista de Economia e Sociologia Rural, 52, 25-44. Recuperado a partir dehttp://www.scielo.br/scielo.php?script=sci_arttext\&pid=S010320032014000600002\&lng=en\&tlng=pt

Yasbek, M. C. (2006). Classes subalternas e assistência social. São Paulo: Cortez. 